\title{
CRISPR-Cas9: a promising tool for gene editing on induced pluripotent stem cells
}

\author{
Eun Ji Kim, Ki Ho Kang, and Ji Hyeon Ju
}

Division of Rheumatology, Department of Internal Medicine, College of Medicine, Seoul St. Mary's Hospital, The Catholic University of Korea, Seoul, Korea

Received: June 24, 2016 Accepted: December 10, 2016

\section{Correspondence to}

Ji Hyeon Ju, M.D.

Division of Rheumatology,

Department of Internal

Medicine, College of Medicine, Seoul St. Mary's Hospital, The

Catholic University of Korea, 222

Banpo-daero, Seocho-gu, Seoul

06591, Korea

Tel: +82-2-2258-6893

Fax: +82-2-3476-2274

E-mail:juji@catholic.ac.kr
Recent advances in genome editing with programmable nucleases have opened up new avenues for multiple applications, from basic research to clinical therapy. The ease of use of the technology_and particularly clustered regularly interspaced short palindromic repeats (CRISPR)—will allow us to improve our understanding of genomic variation in disease processes via cellular and animal models. Here, we highlight the progress made in correcting gene mutations in monogenic hereditary disorders and discuss various CRISPR-associated applications, such as cancer research, synthetic biology, and gene therapy using induced pluripotent stem cells. The challenges, ethical issues, and future prospects of CRISPR-based systems for human research are also discussed.

Keywords: Clustered regularly interspaced short palindromic repeats-Cas9; Clustered regularly interspaced short palindromic repeats; Gene editing; Induced pluripotent stem cells; Genetic therapy

\section{INTRODUCTION}

Socioeconomic burden of rare genetic diseases is increasing. There have been numerous attempts to treat genetic diseases with various methods. However, they were not overly successful till now. Recently, the technology of clustered regularly interspaced short palindromic repeats (CRISPR) emerges as a promising tool to correct genetic abnormalities. This technique is being heralded for precision and accuracy in genetic editing. In this review, we recapitulate the history and recent progress made in the area of CRISPR technology. In the first part of the review, we summarize the history and action mechanism of CRISPR. In the second part of the review, we deliberate upon assorted clinical applications of CRISPR, from the standpoint of recent feasibility and future possibilities. In the third part, we discuss about future perspective of CRISPR technology. Ideal combination of CRISPR technology and induced pluripotent stem cell (iPSC) may bring new CRISPR-based clinical applications into clinics in near future.

\section{PART 1. HISTORY AND MECHANISMS OF ACTION}

In light of the heterogeneity of disease manifestations among patients, the field of precision medicine has attracted a great deal of interest, especially following a new initiative launched in 2015. The Precision Medicine Initiative (PMI), which involves investment in medical research in the United States on a national scale, envisions treatment and prevention of diseases on an individual basis, according to differences in genes and environmental and lifestyle factors $[1,2]$. The short-term goals of 
the PMI include combating cancers, while the accrual of knowledge pertaining to health and diseases represents the long-term focus. The aggregation of personalized information pertaining to genomics, proteomics, and phenotypical parameters is expected not only to provide a better understanding of health and disease, but also to change our approach to risk assessment, diagnostic tests, and therapeutic interventions [3]. However, despite major progress in gene sequencing and profiling, based on advances in technologies such as high-throughput sequencing, precise gene editing remains challenging; this difficulty has hindered the translation of information into clinical applications. As a consequence, the demand for targeted, straightforward, and affordable genetic engineering tools continues to grow.

Over the past several decades, scientists have revolutionized genetic engineering techniques to allow modulation of their function. Since Watson and Crick elucidated the structure of the DNA double helix, many researchers have focused on changing the genome according to particular scientific needs. To achieve this, a platform that can identify the target sequence of interest, specifically cleave that region of the DNA, and alter the sequence at the cleavage site is required. Endogenous site-specific DNA-protein complexes and natural DNA repair pathways from multiple species have been exploited to create various gene engineering toolkits. Among these, the most rapidly evolving technology involves CRISPR and CRISPR-associated nuclease 9 (Cas9) (CRISPR-Cas9), which was selected as Science's Breakthrough of the Year in 2015.

\section{CRISPR-Cas9 in the bacterial adaptive immune system}

CRISPR is derived from the prokaryotic adaptive immune system (Fig. 1) [4-36]. The distinctive clustered repeats were originally recognized in Escherichia coli by Ishino et al. [5] in 1987, and were later found to include unique barcode-like sequences of viral or plasmid origin, termed spacers (Fig. 2) [6-8]. In 2007, the hypothesized role of the repeats in adaptive defense was confirmed by experimental demonstration of spacer integration into the bacterial genome following phage challenge, as well as alteration of sensitivity to subsequent phage infection dependent upon the spacer content [4]. Subsequent studies revealed that CRISPR works in sync with the Cas gene, in the vicinity of the CRISPR locus, to cleave DNA or RNA sequences $[9,10]$ targeted by a small guide RNA [11]. Based on these findings, multiple studies sought to identify the components of the CRISPR-Cas system and apply this knowledge to sequence-specific gene engineering.

\section{Mechanism underlying CRISPR-Cas9 gene editing}

There are six putative CRISPR systems; the three main types (types I to III) were discovered first, with three additional types (types IV to VI) being identified more recently [37,38]. During the processes of immunity, adaptation, expression, and interference, each type acts according to distinct mechanisms to ensure DNA recognition and cleavage [39].

Type I uses a large complex of Cas proteins, encoded by the Cas3 gene, which show separate helicase and DNase activities. Similarly, type III uses repeat-associated mysterious proteins, which constitute a large superfamily of Cas proteins. Types I, III, and IV are categorized as class 1 based on their multi-subunit effector complexes. By contrast, class 2 systems (comprising types II, V, and VI) each have a single-subunit effector. Type II uses only a single protein (Cas9) for its nuclease activity; the same is true for types V and VI, but with Casq-like proteins. Owing to their simplicity, class 2 systems have been adopted for genome engineering [40-42], and only the bacterial type II CRISPR-Cas9 system has been utilized for RNA-guided engineering nucleases [43,44].

As noted above, type II CRISPR-Cas9 systems use a single endonuclease, Cas9. This enzyme acts in concert with two guide RNAs: CRISPR RNA (crRNA) and trans-acting CRISPR RNA (tracrRNA) (Fig. 3) [45]. To simplify the system and improve its utility, scientists employed a linker loop to engineer a dual tracrRNA:crRNA (called single guide RNA [sgRNA]), which participates in sequence-specific DNA cleavage with Cas9 [12]. Short 2 to $5 \mathrm{bp}$ conserved sequences known as proto-spacer adjacent motifs, located on the side opposite to that of the RNA-DNA hybridization, are required for Cas9-DNA recognition [6]. Once recognition occurs, double-stranded DNA cleavage is performed by two Caso domains: the HNH domain, which cleaves the strand complementary to the crRNA-guide sequence, and the RuvC-like domain, which cleaves the noncomplementary strand [12]. Via this mechanism, programmed nucleases with cus- 


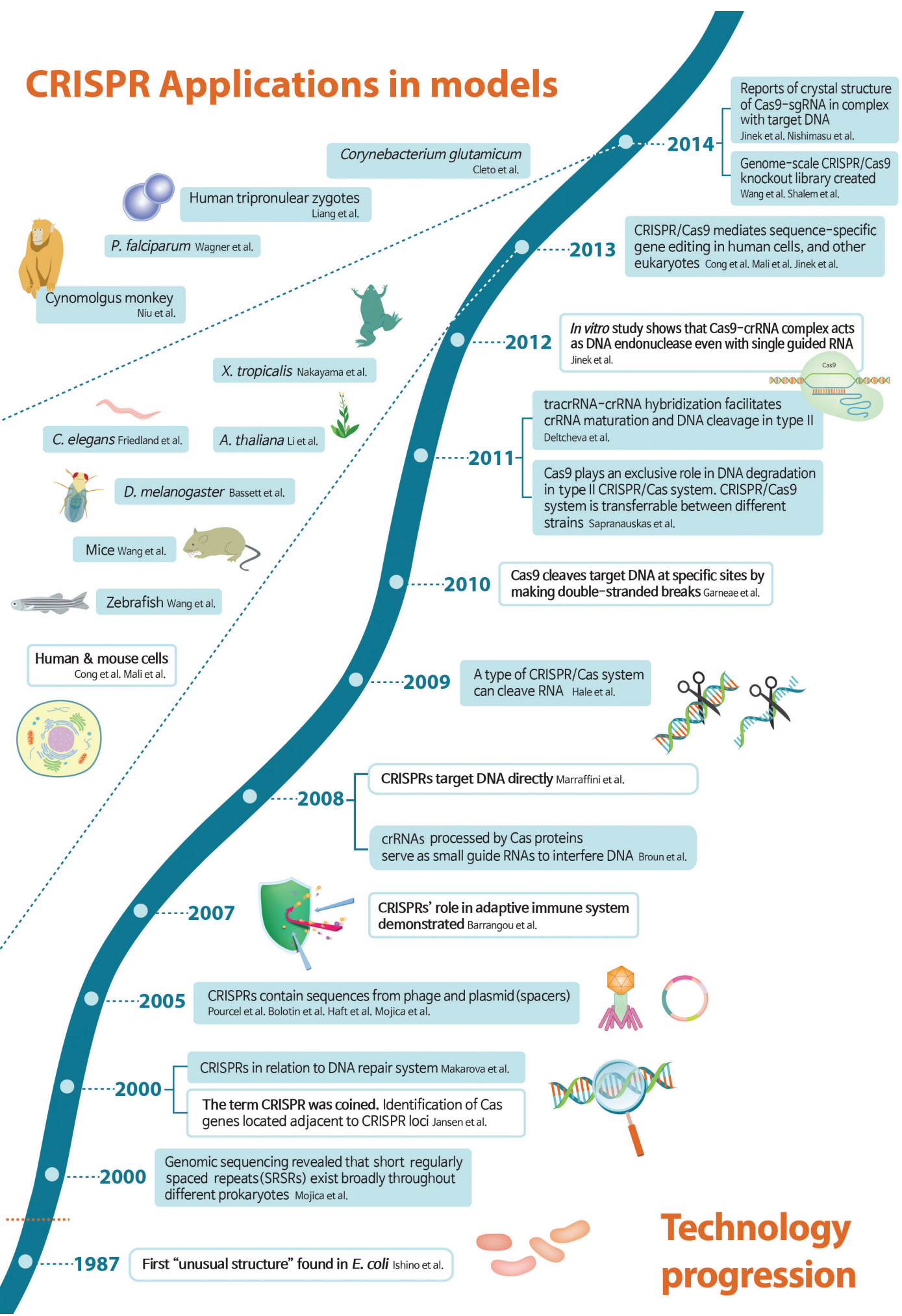

Figure 1. Timeline of technological progression of clustered regularly interspaced short palindromic repeats (CRISPR) and its application in model organisms. Key developments are shown and major breakthroughs are highlighted in white boxes. While the CRISPR story starts in 1987, the name was coined in 2000, and CRISPR's role in adaptive immune system was demonstrated in 2007. A key insight in 2012 that CRISPR-associated nuclease 9 (Cas9) is an RNA-guided DNA endonuclease led to an explosion of papers related to CRISPR gene-editing technology. From 2013, CRISPR was successfully applied in modification of genes in humans and other various organisms [4-36]. sgRNA, single guide RNA; P. falciparum, Plasmodium falciparum; X. tropicalis, Xenopus tropicalis; C. elegans, Caenorhabditis elegans; A. thaliana, Arabidopsis thaliana; D. melanogaster, Drosophila melanogaster; tracrRNA, trans-acting CRISPR RNA; crRNA, CRISPR RNA; E. coli, Escherichia coli. 


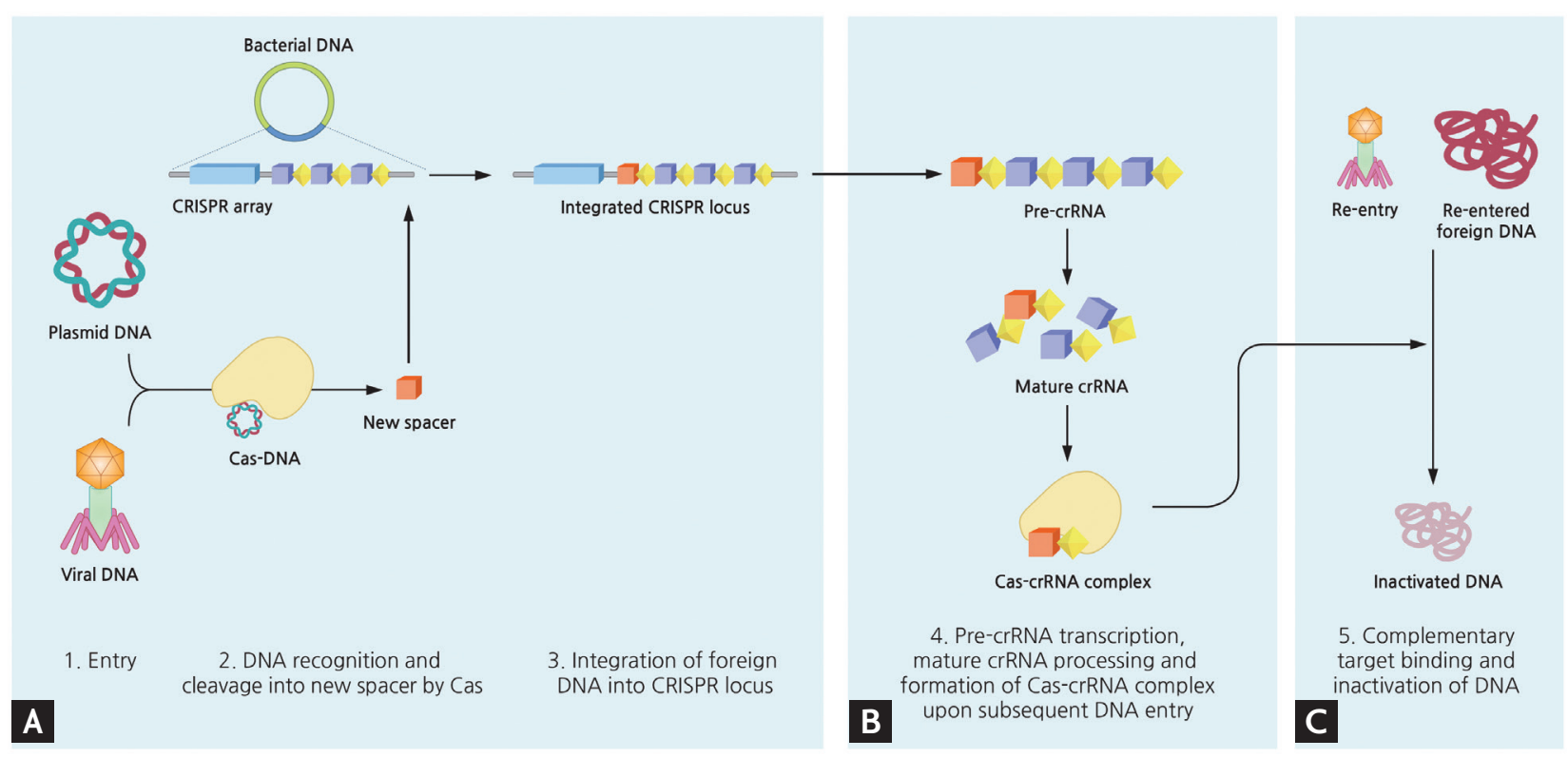

Figure 2. Simplified mechanism of microbial adaptive immune system using clustered regularly interspaced short palindromic repeats (CRISPR). Upon entry of foreign DNA into bacteria, CRISPR-associated (Cas) enzymes acquire new spacers from the exogenous sequence and integrate this spacer unit into the leader end of CRISPR locus within bacterial genome. The transcript of CRISPR array is further processed, and when another corresponding invasion occurs this mature CRISPR RNA (crRNA) act as a guide by Cas complex to degrade matching DNA. The detailed mechanisms of each type of CRISPR systems vary slightly. (A) Acquisition. (B) crRNA biogenesis. (C) Interference.

tomized sgRNA can cleave genomic DNA at specific loci, enabling precise genome editing.

Cas9 protein can be easily re-targeted to new DNA sequences by changing a small portion of the sequence of the accompanying RNA guide, which base-pairs directly with target DNA [46]. Another potential advantage of Caso is its ability to introduce several double-strand breaks (DSBs) within the same genome (also referred to as multiplexing) via the expression of multiple guide RNAs [13,14].

\section{Earlier approaches to gene editing}

Prior to the advent of CRISPR technology, biologists used several generations of tools, all of which employed site-specific DNA DSBs for genome editing. To date, four types of DNA-binding nuclease have been developed: meganucleases, zinc finger nucleases (ZFNs), transcription activator-like effector nucleases (TALENs), and the most recently identified nuclease, Cas9.

Each of the previous tools had unique limitations. Meganucleases are like restriction enzymes but are programmed to target DNA sequences 14 to $40 \mathrm{bp}$ in length. Owing to several shortcomings, including their lack of specificity in DNA recognition and the need to fuse the recognition and cleavage domains, meganucleases were used only briefly [47]. ZFNs and TALENs function according to similar principles, but differ in that their binding domains consist of three- and one-nucleotide recognition modules, respectively. These enzymes have separate DNA-binding domains and nonspecific cleavage domains, namely, FokI endonucleases, making them more efficient than meganucleases $[48,49]$.

However, the construction of ZFNs remains a challenge due to the need to account for context-dependent binding preferences [50], notwithstanding previous efforts to circumvent this shortcoming. TALENs, despite having the advantage of one-to-one binding between the Transcription activator-like effector (TALE) unit and each base pair [51], require painstaking molecular biology cloning methods to synthesize highly conserved and repetitive TALE structures [52]. Consequently, the comparatively facile protein engineering of CRISPR makes this approach much more affordable and practical compared with precursor technologies (Table 1). 


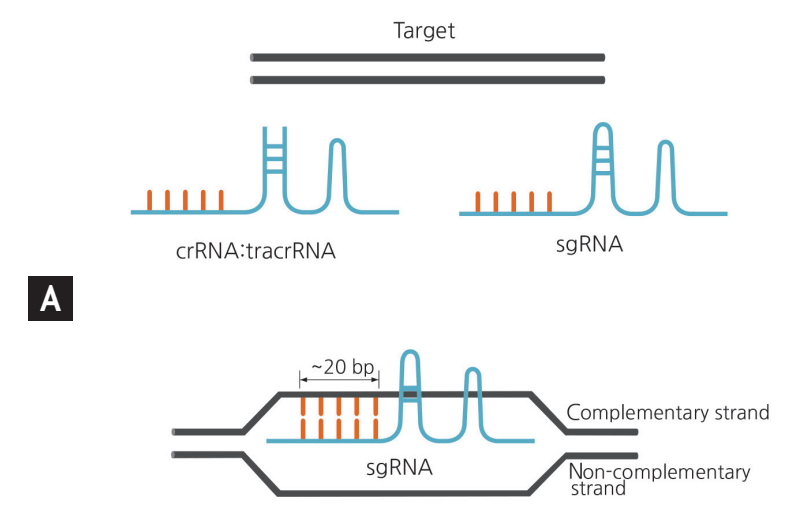

B

c

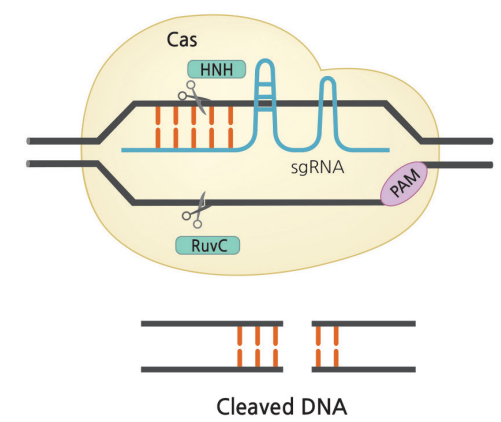

D

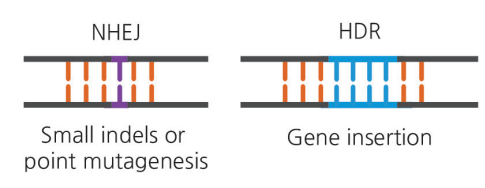

E

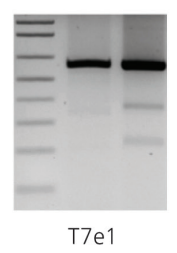

GGIOATACCTITITC

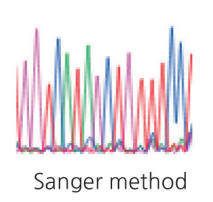

Figure 3. Overview of clustered regularly interspaced short palindromic repeats (CRISPR)-CRISPR-associated nuclease 9 (Cas9) gene editing from target selection and guide design to validation. (A) Select gene of interest and design guide RNA. (B) Base pairing of sgRNA: genomic DNA. (C) Detection of PAM by Cas and cleavage of gene of interest by Cas domains HNH and RuvC. (D) Formation of nuclease-induced double strand breaks (DSB). (E) Validation of gene editing. sgRNA, single guide RNA; crRNA, CRISPR RNA; tracrRNA, trans-acting CRISPR RNA; PAM, proto-spacer adjacent motif; NHEJ, nonhomologous end joining; HDR, homology-directed repair.

\section{PART 2. APPLICATIONS OF CRISPR}

\section{Basic application of the CRISPR-Cas9 system}

When DSBs are introduced, the lesion may be corrected by one of two major repair pathways: homology-directed repair (HDR) or nonhomologous end joining (NHEJ). HDR allows the exchange of genetic information between DNA molecules with similar sequences, whereas NHEJ forms short insertions or deletions (indels) in the target sequence. NHEJ does not require a repair template, but the resultant indels can cause frameshift mutations that lead to the production of nonfunctional, incomplete proteins, or to micro-RNA degradation by nonsense-mediated decay. On the other hand, the HDR machinery can repair DNA using exogenous single- or double-stranded DNA templates with sequence similarity to the DSB site. Thus, exploitation of HDR has allowed researchers to insert new genetic information at a target site, or to perform direct replacement of a mutated gene $[45,46]$.

Although this approach was revolutionary, the natural process of HDR is inefficient because it requires selection and screening to identify the one-in-a-million cell in which homologous recombination has exchanged the wild-type gene for the desired modified version. However, CRISPR-Cas9 technology allows the inducible formation of DSBs, so that scientists can modify gene expression at the repair sitex; thus, opening a new avenue in genome editing [42].

\section{Cell-based and in vivo animal studies}

The applications of CRISPR-Cas9 have expanded into fields such as agricultural products, livestock, disease

Table 1. Comparison of different programmable nucleases

\begin{tabular}{lccc}
\hline Variable & ZFN & TALEN & CRISPR \\
\hline DNA-binding moiety & Protein & Protein & RNA \\
Target site size, bp & $18-36$ & $30-40$ & 22 \\
Nuclease & FokI & FokI & Cas \\
Cytotoxicity & Variable to high & Low & Low \\
Design availability & More complex & Complex & Simple \\
Ease of multiplexing & Low & Low & High \\
\hline
\end{tabular}

ZFN, zinc finger nuclease; TALEN, transcription activator-like effector nuclease; CRISPR, clustered regularly interspaced short palindromic repeats. 
modeling, and therapeutics. In this section, we focus on the therapeutic aspects of gene-based diseases, especially monogenic disorders (Fig. 4).

In gene therapy, genes in diseased cells and tissues can be corrected by two approaches: ex vivo and in vivo editing [46]. In ex vivo therapy, the target cell population is removed from the body, modified using a programmable nuclease, and then transplanted back into the original host; thereby, preventing complications due to immunological rejection. By contrast, in vivo editing therapy involves direct transfer of genome-editing reagents, such as a programmable nuclease and donor templates, into the human body [53]. Each approach has advantages and disadvantages, and they are implemented differently to treat particular disorders. There has been examples of gene-editing techniques applied in disease cell lines (Table 2) [54-77] and in disease mouse models (Table 3) [60,63-66,78-88]. Furthermore, scientists have reported series of therapeutic applications with genome editing using stem cell (Table 4) [89-111].

Inactivation or correction of deleterious mutations

\section{Duchenne muscular dystrophy}

Duchenne muscular dystrophy (DMD) is the most prevalent fatal genetic disease passed on through the $\mathrm{X}$ chromosome. The gene dystrophin consists of 79 exons, and several types of mutation in exon sequences lead to DMD. Currently, there is no effective treatment for DMD, but genome editing has the potential to restore expression of a modified dystrophin gene [53].

Efforts aimed at correction of the dystrophin gene in immortalized patient myoblasts with ZFNs and TALENs were initiated in 2013 [54,55]. Because $13 \%$ of DMD patients have a mutation in exon 51, the introduction of indels into, or complete excision of, exon 51 can restore dystrophin expression [56]. In one study, permanent removal of exons 45 to 55 by multiplexed Cas9 was therapeutically applicable in $62 \%$ of patients [57].

Mouse models can provide data that is relevant to in vivo human therapy. For example, the $M d x$ model mouse harbors a mutation in exon 23 of the dystrophin gene. Local and systemic delivery of gene correction to $\mathrm{Mdx}$ mice using adeno-associated virus (AAV) vector and the CRISPR-Cas9 system resulted in $2 \%$ to $100 \%$ correction, and the therapeutic benefits were predicted to be
$15 \%$ to $20 \%[78-81]$.

Genome editing has also been effective in DMD gene therapy in patients lacking exon 44; in this case, the correction was performed ex vivo in induced pluripotent stem cells (iPSCs). Three correction strategies were tested: skipping of exon 45, introduction of small indels resulting in a frameshift in exon 45 , and knock-in of the missing exon 44 to restore the full protein coding region; the last of these strategies was the most effective. The corrected iPSCs successfully differentiated into muscles and expressed functional protein [89].

Insertion of corrective or protective mutation

\section{Hemophilia}

Hemophilia is caused by different genetic mutationsin coagulation factor VIII (F8) for hemophilia A, and in coagulation factor XI $\left(\mathrm{F}_{9}\right)$ for hemophilia B. Gene therapy is an option for treating hemophilia because correction of the defective gene results in permanent expression of functional protein, and even 1\% wild-type expression of coagulation factor VIII or XI is sufficient to confer a therapeutic effect $[112,113]$.

The first successful in vivo gene targeting of hemophilia was achieved in a hemophilia B neonate mouse [82]. Using a ZFN pair to target the defective human $\mathrm{F}_{9}\left(h \mathrm{~F}_{9}\right)$ gene, and AAV as the delivery vector, donor cDNA was inserted into the mouse genome. A similar approach in adult $\mathrm{hF}_{9}$ mice resulted in stable production of human factor IX [83].

Hemophilia A, which is more prevalent than hemophilia B, involves a more complex type of mutation, making it harder to edit the gene. However, chromosomal inversion at the F8 gene is a common cause of hemophilia, and TALENs were previously shown to be able to correct this rearrangement [90]. Thus, the CRISPR-Cas9 system was used to target each side of the $\sim 600$ $\mathrm{kb}$ inversion and correct the mutation in iPSCs derived from hemophilia A patients [91].

\section{Sickle-cell anemia and $\beta$-thalassemia}

Sickle-cell anemia and $\beta$-thalassemia are both caused by mutations in the $\mathrm{HBB}$ gene, resulting in an inappropriate level of the $\beta$-globin chain of hemoglobin. Editing the $\beta$-globin locus by targeted nucleases represents a new strategy for permanently curing hemoglobinopa- 


\section{Gene editing technique}
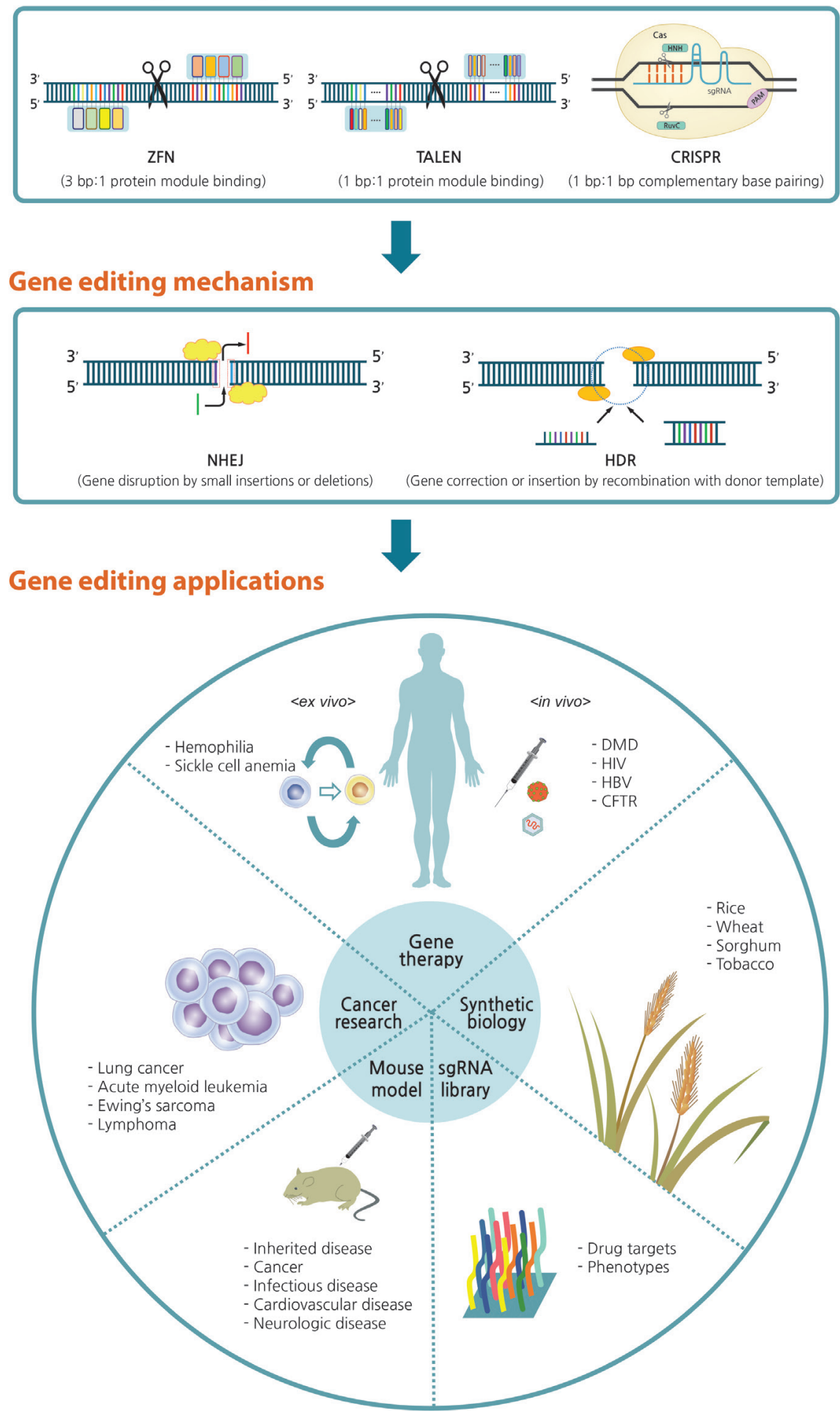

Figure 4. Overview of gene editing and its applications. Genetic defects can be corrected via gene editing with zinc finger nucleases (ZFNs), transcription activator-like effector nucleases (TALENs), and the clustered regularly interspaced short palindromic repeats (CRISPR) system. When double-strand breaks occur, the lesion can be corrected by either nonhomologous end joining (NHEJ) or homology-directed repair (HDR) pathways. Arising from this technique, gene editing can be applied in various fields of research and biotechnology. sgRNA, single guide RNA; PAM, proto-spacer adjacent motif; DMD, Duchenne muscular dystrophy; HIV, human immunodeficiency virus; HBV, hepatitis B virus; CFTR, cystic fibrosis transmembrane conductance regulator. 


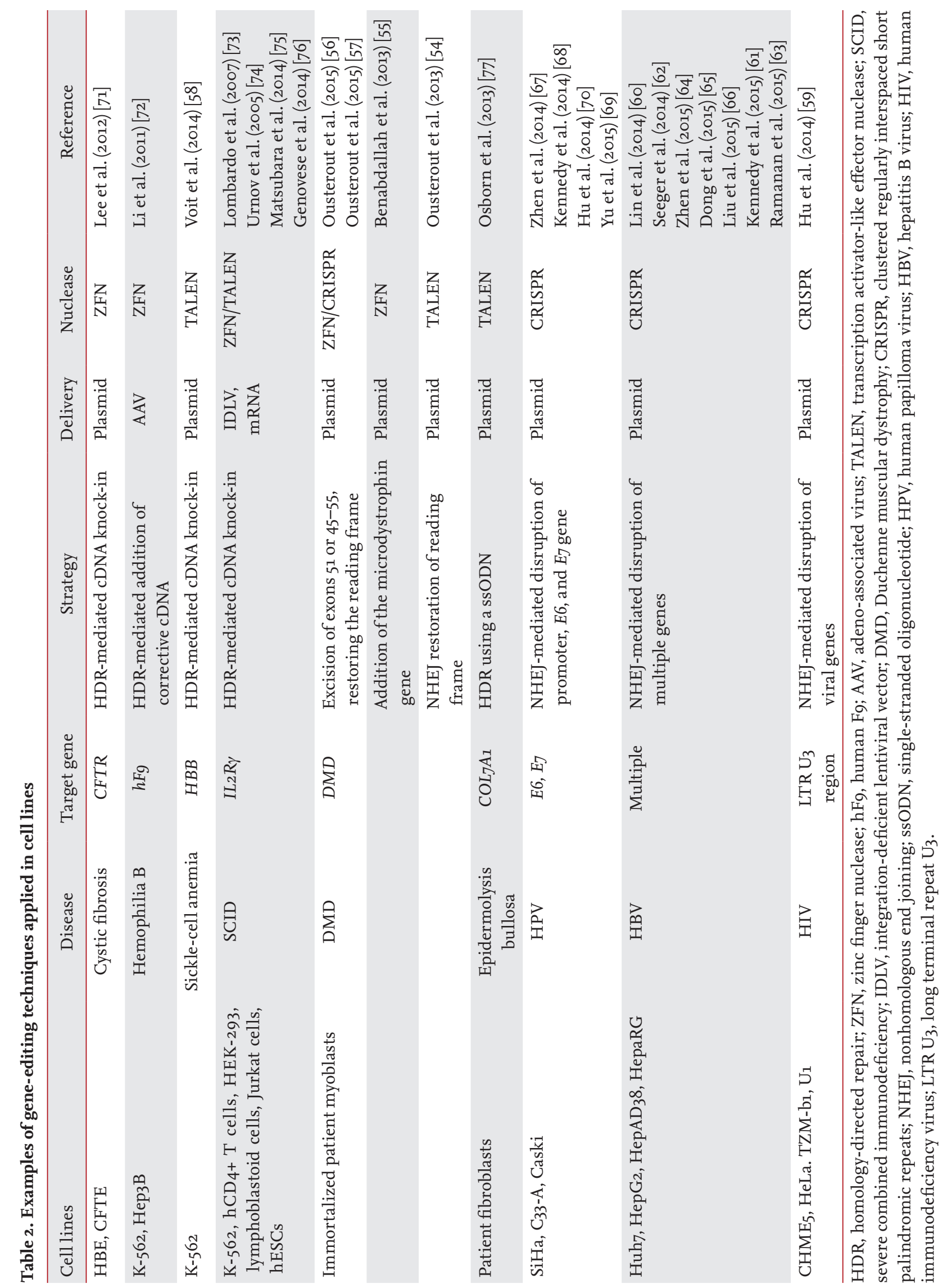


thies. TALENs programmed to target the $\beta$-globin locus were used for HDR-mediated full-length cDNA knockin in $\mathrm{K}_{5} \mathrm{G}_{2}$ cells [58], and ZFNs were used to correct a sickle-cell anemia-associated point mutation in $\mathrm{CD}_{34^{+}}$ hematopoietic stem progenitor cells [92]. These hemoglobinopathies are particularly advantageous for gene therapy because extracted patient iPSCs can be differentiated into hematopoietic stem cells, which can in turn be inserted back into patients by autologous transplantation. This strategy has already been implemented with all ZFNs, TALENs, and CRISPR-Caso in both sickle-cell anemia and $\beta$-thalassemia patients [93-97].

\section{Disruption of viral DNA}

\section{Human immunodeficiency virus}

The most advanced gene-editing strategy is the ex vivo modification of $\mathrm{T}$ cells to knock out the cinnamoyl-CoA reductase $5\left(C^{2} R_{5}\right)$ gene, resulting in resistance to human immunodeficiency virus (HIV) infection. This is one of the few cases in which a treatment that exploits the gene-editing machinery has been used in clinical trials (Table 5). This idea was clinically validated when an HIV-infected patient received a stem cell transplant from a donor with a homozygous deletion in the $\mathrm{CCR}_{5}$ allele, resulting in undetectable levels of HIV and restoration of normal $\mathrm{CD}_{4}{ }^{+} \mathrm{T}$ cell counts [114].

One study demonstrated the safety of infusion of ZFN-modified autologous $\mathrm{CD}_{4}{ }^{+} \mathrm{T}$ cells bearing a deletion of the $\mathrm{CCR}_{5}$ gene into HIV-positive human patients [115]. Building on the results obtained with ZFNs, multiple efforts were made using similar gene-editing strategies to knock out CCR5 using TALENs or CRISPR-Cas9. Wild-type iPSCs were seamlessly modified by NHEJ-mediated deletion of the CCR 5 gene, at an average rate of $14 \%$ with TALENs and $33 \%$ with CRISPR [98]. To increase resistance to HIV infection, other genes were targeted in addition to $\mathrm{CCR}_{5}$, including $\mathrm{C}-\mathrm{X}-\mathrm{C}$ chemokine receptor type 4 (CXCR4), which encodes a coreceptor, and $\mathrm{PC}_{4}$ and SFRS1 interacting protein 1 (PSIP1), which encodes the lens epithelium-derived growth factor (LEDGF)/p75 protein required for HIV integration $[99,116,117]$.

To reduce adverse off-target effects, several studies have attempted to eliminate the integrated HIV-1 genome. In one study, for example, the HIV-1 long ter- minal repeat (LTR) U3 region was efficiently targeted by the CRISPR-Cas9 system, resulting in inactivation of viral gene expression and replication in CHME5, HeLa, TZM-bı, and U1 cells [59].

Beyond HIV, programmable gene-editing nucleases have also been applied to other viral pathogens. For example, in Huh7, HepG2, HepAD38, and HepaRG cells transfected with a hepatitis B virus (HBV) expression vector, targeted editing of multiple genes was used to reduce the production of $\mathrm{HBV}$ core and surface proteins. HBV-expressing templates were disrupted by CRISPR-Cas9 both in vitro and in vivo [60-66]. Likewise, the E6 and Ej genes of human papillomavirus were also targeted by CRISPR-Cas9 [67-70].

There are increasing numbers of ongoing and completed clinical trials adopting gene-editing technology (Table 5).

\section{PART 3. FUTURE PERSPECTIVES}

\section{Cancer research}

All cancers harbor multiple mutations that cause cells to grow progressively and express malignant phenotypes. These mutations can be categorized into four types: oncogenes, tumor suppressors, epigenetic factors and control loci, and chemoresistance genes. The CRISPR-Cas9 system represents a powerful, highly specific and adaptable tool for correcting such mutations and treating the cancers that contain them [118]. While oncogenic changes occur in many cancers and play important roles in malignant cell proliferation, oncogenes such as the receptor tyrosine kinase Erb2 can be targeted directly by CRISPR-Cas9 [119].

From another perspective, it is possible to utilize CRISPR-Cas9 to introduce cancer-causing mutations in human cell lines and animal models. In this context, the following cell lines have been constructed to date: lung cancer [120], acute myeloid leukemia [121], liver cancer [122], and pancreatic cancer [123].

\section{Animal models}

CRISPR-Cas9 technology can be applied to animal models for the study of both cancers and other inherited diseases. Heritable gene modification can be achieved by injecting CRISPR-Cas9, targeting one or multiple alleles, 
Table 3. Examples of therapeutic applications of genome editing in mouse model

\begin{tabular}{|c|c|c|c|c|c|c|}
\hline Disease & Target gene & Strategy & Delivery & Model & Nuclease & Reference \\
\hline $\begin{array}{l}\text { Hemophilia } \\
\text { B }\end{array}$ & $h F_{9}$ & $\begin{array}{l}\text { HDR-mediated } \\
\text { addition of } \\
\text { corrective cDNA }\end{array}$ & AAV & $\begin{array}{l}\text { Humanized } \\
\text { neonatal, } \\
\text { adult mice }\end{array}$ & $\mathrm{ZFN}$ & $\begin{array}{l}\text { Li et al. (2011) [82] } \\
\text { Anguela et al. (2013) [83] }\end{array}$ \\
\hline $\begin{array}{l}\text { Hemophilia } \\
\text { A, B }\end{array}$ & $m A l b$ & $\begin{array}{l}\text { HDR-mediated } \\
\text { insertion of FS and } \\
\text { F9 cDNA, respectively }\end{array}$ & AAV & $\begin{array}{l}\text { Humanized } \\
\text { adult mice }\end{array}$ & & Sharma et al. (2015) [84] \\
\hline $\begin{array}{l}\text { Hereditary } \\
\text { tyrosinemia I }\end{array}$ & Fah & $\begin{array}{l}\text { HDR of point } \\
\text { mutation }\end{array}$ & $\begin{array}{l}\text { Hydrodynamic } \\
\text { injection }\end{array}$ & $\begin{array}{l}\text { Adult mouse } \\
\text { model }\end{array}$ & CRISPR & Yin et al. (2014) [85] \\
\hline Cataract & Crygc & $\begin{array}{l}\text { HDR-mediated } \\
\text { correction }\end{array}$ & Plasmid & $\begin{array}{l}\text { Zygote, mouse } \\
\text { SSC }\end{array}$ & CRISPR & Wu et al. (2015) [81] \\
\hline \multirow[t]{3}{*}{ DMD } & $\begin{array}{l}\text { Exon } 23 \text { of } \\
d m d \text { gene }\end{array}$ & HDR using a ssODN & Cas9, sgRNA & Zygote & CRISPR & Long et al. (2014) [86] \\
\hline & & $\begin{array}{l}\text { NHEJ-mediated } \\
\text { disruption of exon } 23\end{array}$ & AAV & $\begin{array}{l}\text { Adult or } \\
\text { neonatal }\end{array}$ & CRISPR & $\begin{array}{l}\text { Xu et al. (2016) [87], } \\
\text { Nelson et al. (2016) [78] } \\
\text { Tabebordbar et al. (2016) [79] } \\
\text { Long et al. (2016) [80] }\end{array}$ \\
\hline & & $\begin{array}{l}\text { NHEJ-mediated } \\
\text { disruption of exon } 23\end{array}$ & Plasmid & Adult & CRISPR & $\mathrm{Xu}$ et al. (2016) [87] \\
\hline $\mathrm{HBV}$ & Multiple & $\begin{array}{l}\text { NHEJ-mediated } \\
\text { disruption of } \\
\text { multiple genes }\end{array}$ & $\begin{array}{l}\text { Hydrodynamic } \\
\text { injection, } \\
\text { Plasmid }\end{array}$ & Adult & CRISPR & $\begin{array}{l}\text { Lin et al. (2014) [60] } \\
\text { Zhen et al. (2015) [64] } \\
\text { Dong et al. (2015) [65] } \\
\text { Liu et al. (2015) [66] } \\
\text { Ramanan et al. (2015) [63] }\end{array}$ \\
\hline $\begin{array}{l}\text { Cardiovascular } \\
\text { disease }\end{array}$ & Pcskg & $\begin{array}{l}\text { NHEJ-mediated } \\
\text { disruption of PCSK9 }\end{array}$ & Cas9, sgRNA & Adult & CRISPR & Ding et al. (2014) [88] \\
\hline
\end{tabular}

hF9, human F9; HDR, homology-directed repair; AAV, adeno-associated virus; ZFN, zinc finger nuclease; CRISPR, clustered regularly interspaced short palindromic repeats; SSC, spermatogonial stem cell; DMD, Duchenne muscular dystrophy; ssODN, single-stranded oligonucleotide; Cas9, CRISPR associated protein 9; sgRNA, single guide RNA; NHEJ, nonhomologous end joining; HBV, hepatitis B virus.

directly into fertilized zygotes [42]. Among transgenic animal models, mice are the most widely used in experiments because of the relatively short time required to generate mutants; however, non-human primate models have been created successfully by multiplex gene targeting, potentially generating superior systems for the study of complex human diseases, for example, neurodegenerative disorders [124]. Nonetheless, mouse models remain the most cost-effective. Moreover, mice are amenable to large-scale in vivo mutagenesis studies, especially when highly specific targeted editing can avoid the confounding effects of off-target mutagenesis [125].

\section{Synthetic biology}

The applications of the CRISPR-Cas9 system to synthet- ic biology include all concepts related to synthetic gene circuits in living cells. Because synthetic gene circuits consist of sensors, processors, and actuators, synthetic biology has the potential not only to advance basic research, but also to enable practical applications in medicine, biofuel production, and synthesis of commodity chemicals [126]. The most practical applications of the CRISPR-Cas9 system have been in plants, especially crops such as rice, wheat, sorghum, and tobacco. For example, CRISPR-Cas9 was used to target and knock out the mildew-resistance locus (MLO) genes, which encode proteins that repress the defense against powdery mildew disease in hexaploid bread wheat [127]. 


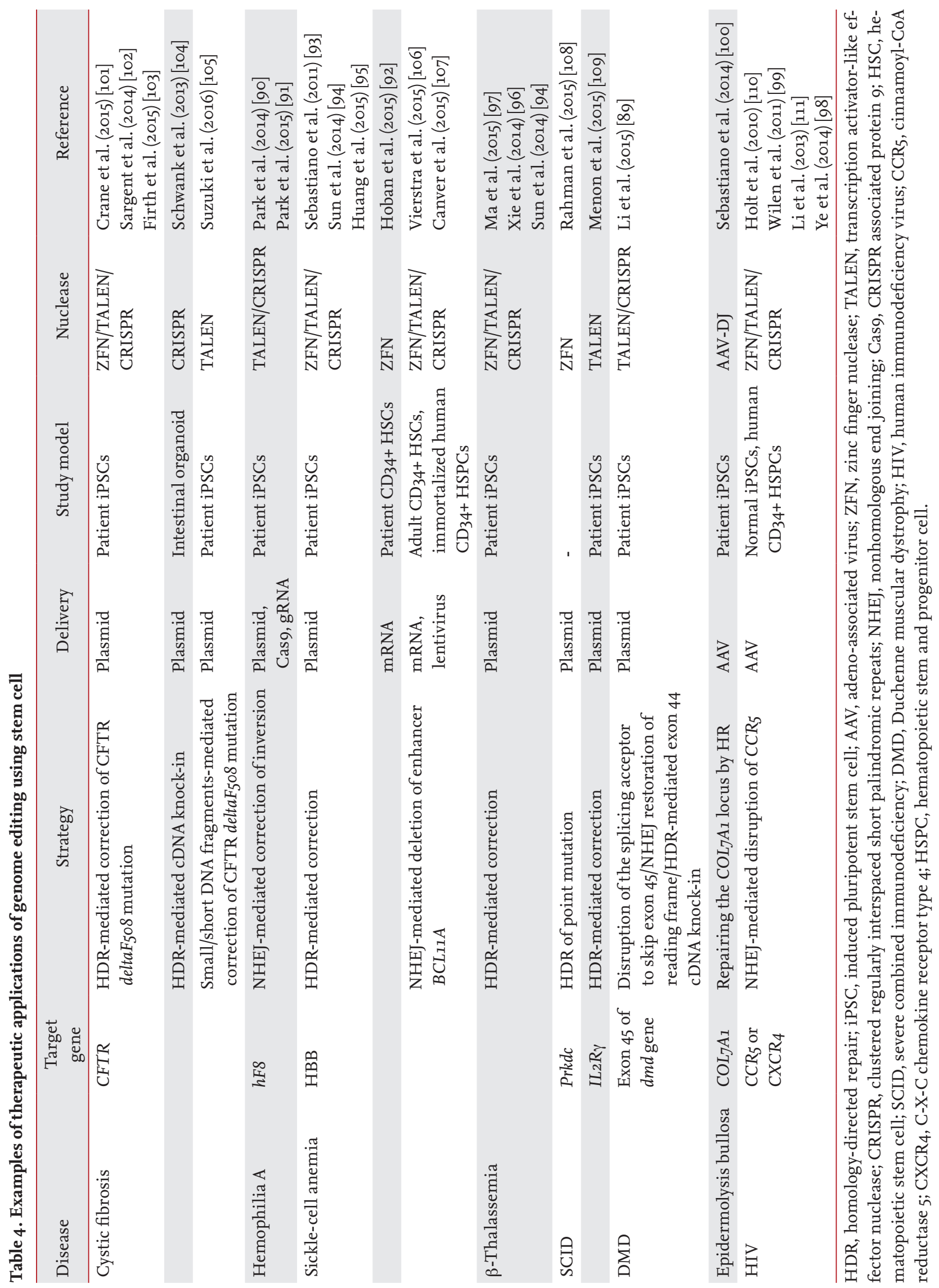


Table 5. Ongoing and completed clinical trials adopting gene-editing technology

\begin{tabular}{|c|c|c|c|c|}
\hline Nuclease & Disease & Status & Phase & Title \\
\hline \multirow[t]{7}{*}{$\mathrm{ZFN}$} & HIV & Completed & I & $\begin{array}{l}\text { Autologous T cells genetically modified at the CCR5 gene by ZFN } \\
\text { SB-728 for HIV }\end{array}$ \\
\hline & & & & $\begin{array}{l}\text { Dose escalation study of autologous T cells genetically modified } \\
\text { at the CCR5 gene by ZFN in HIV-infected patients }\end{array}$ \\
\hline & & & $\mathrm{I} / \mathrm{II}$ & $\begin{array}{l}\text { Study of autologous T cells genetically modified at the CCR5 gene } \\
\text { by ZFN in HIV-infected subjects }\end{array}$ \\
\hline & & Active & $\mathrm{I} / \mathrm{II}$ & $\begin{array}{l}\text { Repeat doses of SB-728mR-T after cyclophosphamide } \\
\text { conditioning in HIV-infected subjects on HAART }\end{array}$ \\
\hline & & Recruiting & I & $\begin{array}{l}\text { Safety study of ZFN CCR5-modified hematopoietic stem/ } \\
\text { progenitor cells in HIV-1 infected patients }\end{array}$ \\
\hline & & & $\mathrm{I} / \mathrm{II}$ & $\begin{array}{l}\text { Dose escalation study of cyclophosphamide in HIV-infected } \\
\text { subjects on HAART receiving SB-722-T }\end{array}$ \\
\hline & Hemophilia B & Not yet recruiting & I & $\begin{array}{l}\text { Ascending dose study of genome editing using the ZFP } \\
\text { therapeutic SB-FIX in subjects with severe hemophilia B }\end{array}$ \\
\hline
\end{tabular}

ZFN, zinc finger nuclease; HIV, human immunodeficiency virus; CCR5, cinnamoyl-CoA reductase 5.

\section{sgRNA library}

CRISPR-Cas9 can also be applied to the systematic analysis of gene functions in human cells. A lentiviral sgRNA library was developed against genes identified by functional screening and high-throughput sequencing analysis. This powerful loss-of-function library screening is expected to facilitate discovery of genes that participate in various biological processes, including drug targeting, toxicity, and expression of certain phenotypes [128].

\section{Induced pluripotent stem cells}

iPSCs, which are very similar to embryonic stem cells, are pluripotent cells with a high self-renewal rate that can differentiate into almost all cell types; however, their utilization is associated with significantly less ethical controversy than that of their embryonic counterparts. Recent advances in stem cell technology are likely to provide great benefits to the clinical use of iPSCs in clinical applications [129].

As mentioned above, iPSCs have a major advantage for personalized medicine because they can be derived from the patients themselves, and can therefore avoid immune rejection when transplanted. Ex vivo therapy includes correction of patient-derived iPSCs through gene editing, as well as differentiation into nonrenewable cell types such as neurons and cardiomyocytes (Fig. 5) $[100]$.

In addition to this type of precision therapy, human
iPSC lines with genotypes characteristic of specific diseases could be used to understand pathogenic mechanisms. Disease modeling and drug efficiency/toxicity testing with iPSCs not only increase the accuracy of disease simulation, but are also less expensive than generating animal models. However, care must be taken when interpreting the results of phenotypic comparisons between patient iPSC-derived cells and healthy control cells. Specifically, the results are vulnerable to confounding variables that might influence the phenotypes of interest, including epigenetic status and unmatched age, gender, and ethnicity. In this respect, gene editing is the only way to distinguish changes that are specifically relevant to a given disease [130].

The CRISPR-Cas9 system enables simultaneous knockout of multiple genes, as well as knock-in of specific alleles in iPSCs, distinguishing it from earlier gene-editing technologies such as ZFNs and TALENs. An isogenic human iPSC cell line precisely corrected by the CRISPR-Cas9 system was recently constructed, despite the handling difficulties associated with gene editing of human stem cells [131]. In the future, the use of CRISPR-Cas9 with iPSCs will lead to novel combinations of gene and cell therapies [132].

\section{Areas of technical improvement: DSB repair, nucle- ases, delivery}

Prior to the clinical application of CRISPR-Cas9 in 


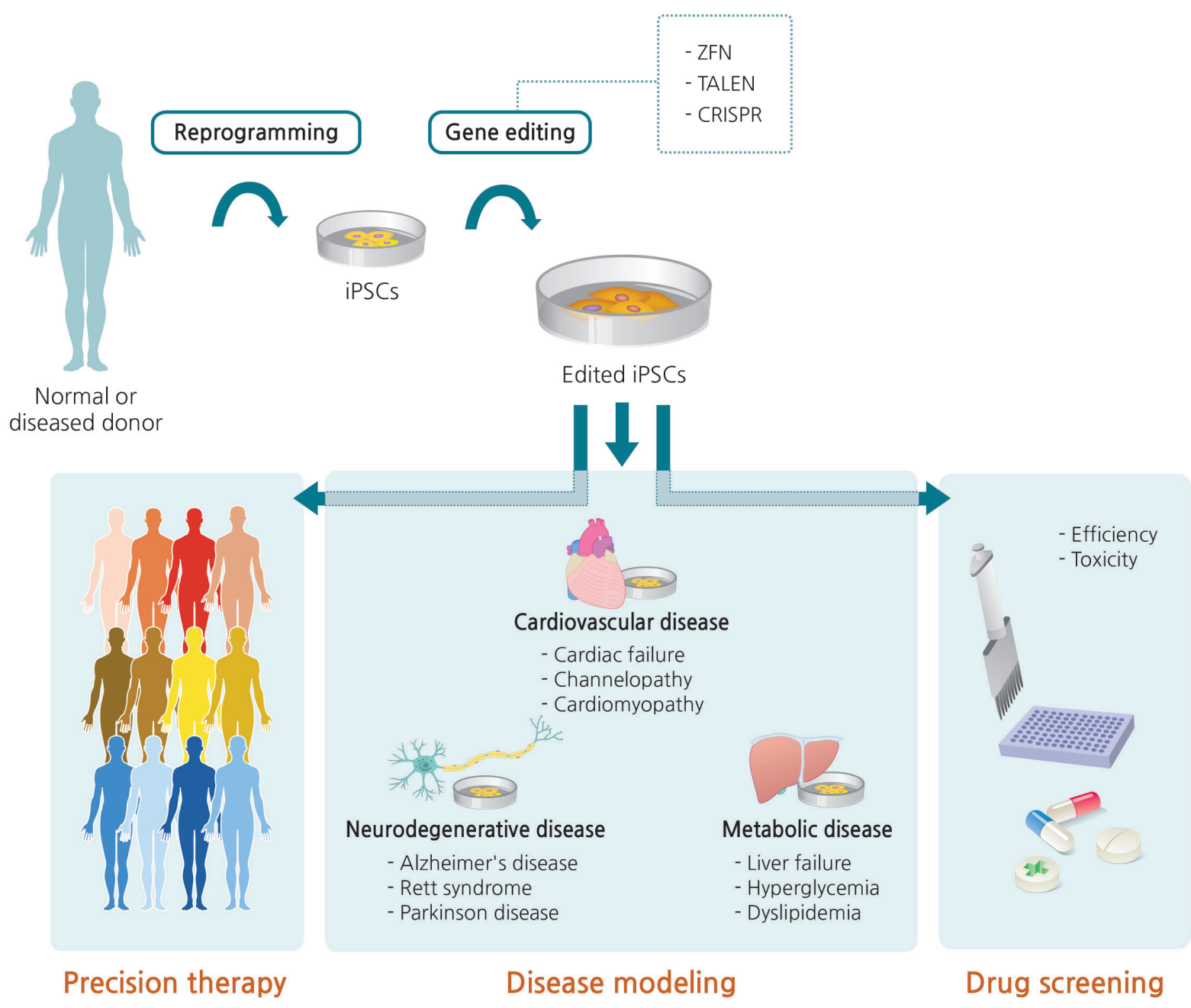

Figure 5. Generation of edited induced pluripotent stem cells (iPSCs) and clinical applications thereof. Somatic cells isolated from a normal person or patient are reprogrammed into iPSCs. Normal sequence can be disrupted or genetic defects can be corrected via gene editing. iPSCs with edited modifications are differentiated into various target cells for disease modeling, which can provide a useful channel for precision therapy and drug screening. ZFN, zinc finger nuclease; TALEN, transcription activator-like effector nuclease; CRISPR, clustered regularly interspaced short palindromic repeats.

human patients, the safety and efficacy of the system must be validated. The specificity and efficiency of genome-editing tools can be improved by targeting DSB repair pathways, modifying nucleases, and changing the mode of delivery. We briefly discuss each topic below.

\section{DSB repair}

As noted previously, DNA editing rates are currently determined by the two major endogenous DSB repair pathways. HDR is more suitable for gene correction or gene insertion than NHEJ, which creates indels that generally induce a loss of function. NHEJ is more effi- cient because it is active throughout the cell cycle and does not require a repair template; by contrast, the rate of HDR is inherently low. In addition, some HDR components are expressed only during the $S / G_{2}$ phase, limiting the use of HDR-based editing approaches to dividing cells and preventing their use in post-mitotic cells, such as neurons and cardiac myocytes. For this reason, controlling the efficiency of HDR has become a major focus of efforts aimed at increasing the effectiveness of gene correction [46].

One strategy for improving the efficiency of HDR is the suppression of NHEJ during DSB repair. Suppres- 
sion of a key enzyme in the NHEJ pathway increases the efficiency of HDR-mediated genome editing up to 19-fold [133,134]. Another strategy involves the induction of HDR-like corrections in post-mitotic cells via a novel non-HDR-based pathway: microhomology-mediated end joining [135,136]. Using microhomologous sequences ( 5 to $25 \mathrm{bp}$ ), the so-called PITCH (Precise Integration into Target Chromosome) system can produce precise gene knock-ins. Meanwhile, the lower success rate of CRISPR-Cas9 relative to TALEN could be overcome by the generation of sticky, instead of blunt, ends [137].

\section{Nucleases}

From a clinical standpoint, highly specific gene engineering technology is essential because specificity is correlated with safety. Unexpected off-target mutations may cause cells to become carcinogenic or functionally impotent. Because genetic modifications are permanent, multiple ongoing research efforts are devoted to the reduction of off-target effects.

One strategy for achieving this goal is to improve the targeting specificity of Cas9. Careful design of sgRNA, including avoidance of poly-G/poly-C-rich targets, as well as tight control of the amount and duration of Cas9 and sgRNA expression, are both important for high specificity [138]. The use of modified Cas9 with two separate sgRNAs that each generate a single-strand nick on opposing DNA strands can potentially reduce off-target activity by 50 - to 1,500-fold in cell lines [139,140]. Additionally, truncation of the guide RNA, with a target-complementary region shorter than 20 nucleotides in length, can decrease off-target activity by 5,000-fold or more [141]. Moreover, a fusion protein of catalytically inactive Cas9 and FokI nuclease (fCas9) can recognize the target DNA site with 140-fold greater specificity than the wild-type protein in human cells [142,143].

\section{Delivery}

The delivery of gene-editing tools to target cells is another major challenge with respect to efficacy and specificity. Both viral and nonviral delivery methods are currently being evaluated for the introduction of Caso into target cells ex vivo or in vivo. Depending on the mode of delivery and the duration of nuclease expression, both off-target activities and immune reactions are possible.

Viral vectors, such as AAV or lentivirus, represent the most common delivery systems, and these vectors have recently been approved for clinical use. In particular, $\mathrm{AAV}$, which was recently clinically approved, is an attractive candidate for in vivo use because of its low degree of immune stimulation, well-characterized serotypes, and ability to target diverse tissues such as eye, brain liver, and muscle [144]. However, one challenge of using AAV is its relatively small packaging capacity (4.7 kb). Consequently, efforts are underway to deliver the Cas9 and sgRNA coding sequences using two separate AAV vectors. Alternatively, these size constraints can be sidestepped by creating a shorter Cas9 ortholog. In addition to size incompatibility, viral vectors have the drawback of possible constitutive nuclease expression, resulting in cell toxicity and genomic instability [145].

A variety of nonviral methods exist for both in vivo and ex vivo delivery of CRISPR-Cas9 in the form of mRNA or proteins [146]; these include electroporation, hydrodynamic delivery, and the use of liposomes [147]. Because mRNA and proteins introduced by these methods are present in cells only transiently, nonviral delivery systems are expected to decrease the frequency of off-target effects and cell toxicity relative to viral systems.

\section{Ethics}

As promising as CRISPR sounds, a variety of concerns have been expressed about this technique. In early 2015 , a Chinese research group used CRISPR-Cas9 to perform editing on nonviable human trinuclear zygotes, stimulating a vigorous discussion of the ethical implications. The International Summit on Human Gene Editing in Washington was convened in late 2015, providing a forum in which scientists could achieve a consensus on human germline engineering.

The CRISPR-Cas9 toolbox has many advantages and it can be used to correct many defects that occur systemically or from birth, including cystic fibrosis and Huntington's disease. However, it remains unclear how we should set boundaries regarding which human traits are appropriate for editing. In addition, few would argue that a number of safety and efficacy concerns about CRISPR-Cas9 remain to be resolved. Especially in light of the possibility that undesirable parties could use this technology for eugenics, it would be irresponsible to allow modification of human embryos. In this respect, we must confront the need for robust regulation, even as 
arguments rage between the advocates of caution and progress.

\section{CONCLUSIONS}

Recent advances in genome editing with CRISPR is very rapid from basic research to clinical therapy. Development of CRISPR may widen the opportunity of iPSC application in real clinic. To deeply understand cutting-edge CRISPR technology can promote gene-editing applications in fields of cancer research, synthetic biology, and gene therapy using induced pluripotent stem cells.

\section{Conflict of interest}

No potential conflict of interest relevant to this article was reported.

\section{Acknowledgments}

This work was supported by a grant from the Basic Science Research Program through the National Research Foundation of Korea (NRF), funded by the Ministry of Science, ICT and Future Planning (2013R1A1A1076125).

\section{REFERENCES}

1. Collins FS, Varmus H. A new initiative on precision medicine. N Engl J Med 2015;372:793-795.

2. Lander ES. Cutting the Gordian helix: regulating genomic testing in the era of precision medicine. N Engl J Med 2015;372:1185-1186.

3. Jameson JL, Longo DL. Precision medicine: personalized, problematic, and promising. N Engl J Med 2015;372:22292234 .

4. Barrangou R, Fremaux C, Deveau H, et al. CRISPR provides acquired resistance against viruses in prokaryotes. Science 2007;315:1709-1712.

5. Ishino Y, Shinagawa H, Makino K, Amemura M, Nakata A. Nucleotide sequence of the iap gene, responsible for alkaline phosphatase isozyme conversion in Escherichia coli, and identification of the gene product. J Bacteriol 1987;169:5429-5433.

6. Bolotin A, Quinquis B, Sorokin A, Ehrlich SD. Clustered regularly interspaced short palindrome repeats (CRISPRs) have spacers of extrachromosomal origin. Microbiology 2005;151(Pt 8):2551-2561.

7. Mojica FJ, Diez-Villasenor C, Garcia-Martinez J, Soria E. Intervening sequences of regularly spaced prokaryotic repeats derive from foreign genetic elements. J Mol Evol 2005;60:174-182.

8. Pourcel C, Salvignol G, Vergnaud G. CRISPR elements in Yersinia pestis acquire new repeats by preferential uptake of bacteriophage DNA, and provide additional tools for evolutionary studies. Microbiology 2005;151(Pt 3):653-663.

9. Marraffini LA, Sontheimer EJ. CRISPR interference limits horizontal gene transfer in staphylococci by targeting DNA. Science 2008;322:1843-1845.

10. Hale CR, Zhao P, Olson S, et al. RNA-guided RNA cleavage by a CRISPR RNA-Cas protein complex. Cell 2009;139:945956.

11. Brouns SJ, Jore MM, Lundgren M, et al. Small CRISPR RNAs guide antiviral defense in prokaryotes. Science 2008;321:960-964.

12. Jinek M, Chylinski K, Fonfara I, Hauer M, Doudna JA, Charpentier E. A programmable dual-RNA-guided DNA endonuclease in adaptive bacterial immunity. Science 2012;337:816-821.

13. Cong L, Ran FA, Cox D, et al. Multiplex genome engineering using CRISPR/Cas systems. Science 2013;339:819-823.

14. Mali P, Yang L, Esvelt KM, et al. RNA-guided human genome engineering via Cas9. Science 2013;339:823-826.

15. Mojica FJ, Diez-Villasenor C, Soria E, Juez G. Biological significance of a family of regularly spaced repeats in the genomes of Archaea, Bacteria and mitochondria. Mol Microbiol 2000;36:244-246.

16. Jansen R, Embden JD, Gaastra W, Schouls LM. Identification of genes that are associated with DNA repeats in prokaryotes. Mol Microbiol 2002;43:1565-1575.

17. Makarova KS, Aravind L, Grishin NV, Rogozin IB, Koonin EV. A DNA repair system specific for thermophilic Archaea and bacteria predicted by genomic context analysis. Nucleic Acids Res 2002;30:482-496.

18. Haft DH, Selengut J, Mongodin EF, Nelson KE. A guild of 45 CRISPR-associated (Cas) protein families and multiple CRISPR/Cas subtypes exist in prokaryotic genomes. PLoS Comput Biol 2005;1:e6o.

19. Garneau JE, Dupuis ME, Villion M, et al. The CRISPR/ Cas bacterial immune system cleaves bacteriophage and plasmid DNA. Nature 2010;468:67-71.

20. Deltcheva E, Chylinski K, Sharma CM, et al. CRISPR RNA 
maturation by trans-encoded small RNA and host factor RNase III. Nature 2011;471:602-607.

21. Sapranauskas R, Gasiunas G, Fremaux C, Barrangou R, Horvath P, Siksnys V. The Streptococcus thermophilus CRISPR/Cas system provides immunity in Escherichia coli. Nucleic Acids Res 2011;39:9275-9282.

22. Jinek M, East A, Cheng A, Lin S, Ma E, Doudna J. RNAprogrammed genome editing in human cells. Elife 2013;2:e00471.

23. Hwang WY, Fu Y, Reyon D, et al. Efficient genome editing in zebrafish using a CRISPR-Cas system. Nat Biotechnol 2013;31:227-229.

24. Wang H, Yang H, Shivalila CS, et al. One-step generation of mice carrying mutations in multiple genes by CRISPR/ Cas-mediated genome engineering. Cell 2013;153:910-918.

25. Bassett AR, Tibbit C, Ponting CP, Liu JL. Highly efficient targeted mutagenesis of Drosophila with the CRISPR/ Cas9 system. Cell Rep 2013;4:220-228.

26. Friedland AE, Tzur YB, Esvelt KM, Colaiacovo MP, Church GM, Calarco JA. Heritable genome editing in C. elegans via a CRISPR-Cas9 system. Nat Methods 2013;10:741-743.

27. Li JF, Norville JE, Aach J, et al. Multiplex and homologous recombination-mediated genome editing in Arabidopsis and Nicotiana benthamiana using guide RNA and Cas9. Nat Biotechnol 2013;31:688-691.

28. Nakayama T, Fish MB, Fisher M, Oomen-Hajagos J, Thomsen GH, Grainger RM. Simple and efficient CRISPR/Cas9-mediated targeted mutagenesis in Xenopus tropicalis. Genesis 2013;51:835-843.

29. Jinek M, Jiang F, Taylor DW, et al. Structures of Cas9 endonucleases reveal RNA-mediated conformational activation. Science 2014;343:1247997.

30. Nishimasu H, Ran FA, Hsu PD, et al. Crystal structure of Cas9 in complex with guide RNA and target DNA. Cell 2014;156:935-949.

31. Wang T, Wei JJ, Sabatini DM, Lander ES. Genetic screens in human cells using the CRISPR-Cas9 system. Science 2014;343:80-84.

32. Shalem O, Sanjana NE, Hartenian E, et al. Genome-scale CRISPR-Cas9 knockout screening in human cells. Science 2014;343:84-87.

33. Niu Y, Shen B, Cui Y, et al. Generation of gene-modified cynomolgus monkey via Cas9/RNA-mediated gene targeting in one-cell embryos. Cell 2014;156:836-843.

34. Wagner JC, Platt RJ, Goldfless SJ, Zhang F, Niles JC. Efficient CRISPR-Cas9-mediated genome editing in Plasmo- dium falciparum. Nat Methods 2014;11:915-918.

35. Liang P, Xu Y, Zhang X, et al. CRISPR/Cas9-mediated gene editing in human tripronuclear zygotes. Protein Cell 2015;6:363-372.

36. Cleto S, Jensen JV, Wendisch VF, Lu TK. Corynebacterium glutamicum metabolic engineering with CRISPR interference (CRISPRi). ACS Synth Biol 2016;5:375-385.

37. Wright AV, Nunez JK, Doudna JA. Biology and applications of CRISPR systems: harnessing nature's toolbox for genome engineering. Cell 2016;164:29-44.

38. Shmakov S, Abudayyeh OO, Makarova KS, et al. Discovery and functional characterization of diverse class 2 CRISPR-Cas systems. Mol Cell 2015;60:385-397.

39. Doudna JA, Charpentier E. Genome editing: the new frontier of genome engineering with CRISPR-Cas9. Science 2014;346:1258096.

40. Makarova KS, Haft DH, Barrangou R, et al. Evolution and classification of the CRISPR-Cas systems. Nat Rev Microbiol 2011;9:467-477.

41. Makarova KS, Wolf YI, Alkhnbashi OS, et al. An updated evolutionary classification of CRISPR-Cas systems. Nat Rev Microbiol 2015;13:722-736.

42. Lander ES. The heroes of CRISPR. Cell 2016;164:18-28.

43. Charpentier E, Richter H, van der Oost J, White MF. Biogenesis pathways of RNA guides in archaeal and bacterial CRISPR-Cas adaptive immunity. FEMS Microbiol Rev 2015;39:428-441.

44. $\mathrm{Kim} \mathrm{H}, \mathrm{Kim} J \mathrm{~S}$. A guide to genome engineering with programmable nucleases. Nat Rev Genet 2014;15:321-334.

45. Charpentier E, Doudna JA. Biotechnology: rewriting a genome. Nature 2013;495:50-51.

46. Cox DB, Platt RJ, Zhang F. Therapeutic genome editing: prospects and challenges. Nat Med 2015;21:121-131.

47. Silva G, Poirot L, Galetto R, et al. Meganucleases and other tools for targeted genome engineering: perspectives and challenges for gene therapy. Curr Gene Ther 2011;11:11-27.

48. Urnov FD, Rebar EJ, Holmes MC, Zhang HS, Gregory PD. Genome editing with engineered zinc finger nucleases. Nat Rev Genet 2010;11:636-646.

49. Christian M, Cermak T, Doyle EL, et al. Targeting DNA double-strand breaks with TAL effector nucleases. Genetics 2010;186:757-761.

50. Maeder ML, Thibodeau-Beganny S, Osiak A, et al. Rapid "open-source" engineering of customized zinc-finger nucleases for highly efficient gene modification. Mol Cell 
2008;31:294-301.

51. Moscou MJ, Bogdanove AJ. A simple cipher governs DNA recognition by TAL effectors. Science 2009;326:1501.

52. Joung JK, Sander JD. TALENs: a widely applicable technology for targeted genome editing. Nat Rev Mol Cell Biol 2013;14:49-55.

53. Prakash V, Moore M, Yanez-Munoz RJ. Current progress in therapeutic gene editing for monogenic diseases. Mol Ther 2016;24:465-474.

54. Ousterout DG, Perez-Pinera P, Thakore PI, et al. Reading frame correction by targeted genome editing restores dystrophin expression in cells from Duchenne muscular dystrophy patients. Mol Ther 2013;21:1718-1726.

55. Benabdallah BF, Duval A, Rousseau J, et al. Targeted gene addition of microdystrophin in mice skeletal muscle via human myoblast transplantation. Mol Ther Nucleic Acids 2013;2:e68.

56. Ousterout DG, Kabadi AM, Thakore PI, et al. Correction of dystrophin expression in cells from Duchenne muscular dystrophy patients through genomic excision of exon 51 by zinc finger nucleases. Mol Ther 2015;23:523-532.

57. Ousterout DG, Kabadi AM, Thakore PI, Majoros WH, Reddy TE, Gersbach CA. Multiplex CRISPR/Caso-based genome editing for correction of dystrophin mutations that cause Duchenne muscular dystrophy. Nat Commun 2015;6:6244.

58. Voit RA, Hendel A, Pruett-Miller SM, Porteus MH. Nuclease-mediated gene editing by homologous recombination of the human globin locus. Nucleic Acids Res 2014;42:1365-1378.

59. Hu W, Kaminski R, Yang F, et al. RNA-directed gene editing specifically eradicates latent and prevents new HIV-1 infection. Proc Natl Acad Sci U S A 2014;111:11461-11466.

6o. Lin SR, Yang HC, Kuo YT, et al. The CRISPR/Cas9 system facilitates clearance of the intrahepatic HBV templates in vivo. Mol Ther Nucleic Acids 2014;3:e186.

61. Kennedy EM, Bassit LC, Mueller H, et al. Suppression of hepatitis B virus DNA accumulation in chronically infected cells using a bacterial CRISPR/Cas RNA-guided DNA endonuclease. Virology 2015;476:196-205.

62. Seeger C, Sohn JA. Targeting hepatitis B virus with CRISPR/Cas9. Mol Ther Nucleic Acids 2014;3:e216.

63. Ramanan V, Shlomai A, Cox DB, et al. CRISPR/Cas9 cleavage of viral DNA efficiently suppresses hepatitis B virus. Sci Rep 2015;5:10833.

64. Zhen S, Hua L, Liu YH, et al. Harnessing the clustered regularly interspaced short palindromic repeat (CRISPR)/ CRISPR-associated Cas9 system to disrupt the hepatitis B virus. Gene Ther 2015;22:404-412.

65. Dong C, Qu L, Wang H, Wei L, Dong Y, Xiong S. Targeting hepatitis B virus cccDNA by CRISPR/Cas9 nuclease efficiently inhibits viral replication. Antiviral Res 2015;118:110-117.

66. Liu X, Hao R, Chen S, Guo D, Chen Y. Inhibition of hepatitis $\mathrm{B}$ virus by the CRISPR/Cas9 system via targeting the conserved regions of the viral genome. J Gen Virol 2015;96:2252-2261.

67. Zhen S, Hua L, Takahashi Y, Narita S, Liu YH, Li Y. In vitro and in vivo growth suppression of human papillomavirus 16-positive cervical cancer cells by CRISPR/Cas9. Biochem Biophys Res Commun 2014;450:1422-1426.

68. Kennedy EM, Kornepati AV, Goldstein M, et al. Inactivation of the human papillomavirus E6 or E7 gene in cervical carcinoma cells by using a bacterial CRISPR/Cas RNA-guided endonuclease. J Virol 2014;88:11965-11972.

69. Yu L, Wang X, Zhu D, et al. Disruption of human papillomavirus 16 E6 gene by clustered regularly interspaced short palindromic repeat/Cas system in human cervical cancer cells. Onco Targets Ther 2015;8:37-44.

70. Hu Z, Yu L, Zhu D, et al. Disruption of HPV16-E7 by CRISPR/Cas system induces apoptosis and growth inhibition in HPV16 positive human cervical cancer cells. Biomed Res Int 2014;2014:612823.

71. Lee CM, Flynn R, Hollywood JA, Scallan MF, Harrison PT. Correction of the deltaF508 mutation in the cystic fibrosis transmembrane conductance regulator gene by zinc-finger nuclease homology-directed repair. Biores Open Access 2012;1:99-108.

72. Li XB, Chen J, Deng MJ, Wang F, Du ZW, Zhang JW. Zinc finger protein $\mathrm{HZF}_{1}$ promotes $\mathrm{K}_{5} 62$ cell proliferation by interacting with and inhibiting INCA1. Mol Med Rep 2011;4:1131-1137.

73. Lombardo A, Genovese P, Beausejour CM, et al. Gene editing in human stem cells using zinc finger nucleases and integrase-defective lentiviral vector delivery. Nat Biotechnol 2007;25:1298-1306.

74. Urnov FD, Miller JC, Lee YL, et al. Highly efficient endogenous human gene correction using designed zinc-finger nucleases. Nature 2005;435:646-651.

75. Matsubara Y, Chiba T, Kashimada K, et al. Transcription activator-like effector nuclease-mediated transduction of exogenous gene into IL2RG locus. Sci Rep 2014;4:5043. 
76. Genovese P, Schiroli G, Escobar G, et al. Targeted genome editing in human repopulating haematopoietic stem cells. Nature 2014;510:235-240.

77. Osborn MJ, Starker CG, McElroy AN, et al. TALEN-based gene correction for epidermolysis bullosa. Mol Ther 2013;21:1151-1159.

78. Nelson CE, Hakim CH, Ousterout DG, et al. In vivo genome editing improves muscle function in a mouse model of Duchenne muscular dystrophy. Science 2016;351:403407.

79. Tabebordbar M, Zhu K, Cheng JK, et al. In vivo gene editing in dystrophic mouse muscle and muscle stem cells. Science 2016;351:407-411.

8o. Long C, Amoasii L, Mireault AA, et al. Postnatal genome editing partially restores dystrophin expression in a mouse model of muscular dystrophy. Science 2016;351:400403.

81. Wu Y, Zhou H, Fan X, et al. Correction of a genetic disease by CRISPR-Cas9-mediated gene editing in mouse spermatogonial stem cells. Cell Res 2015;25:67-79.

82. Li H, Haurigot V, Doyon Y, et al. In vivo genome editing restores haemostasis in a mouse model of haemophilia. Nature 2011;475:217-221.

83. Anguela XM, Sharma R, Doyon Y, et al. Robust ZFN-mediated genome editing in adult hemophilic mice. Blood 2013;122:3283-3287.

84. Sharma R, Anguela XM, Doyon Y, et al. In vivo genome editing of the albumin locus as a platform for protein replacement therapy. Blood 2015;126:1777-1784.

85. Yin H, Xue W, Chen S, et al. Genome editing with Cas9 in adult mice corrects a disease mutation and phenotype. Nat Biotechnol 2014;32:551-553.

86. Long C, McAnally JR, Shelton JM, Mireault AA, Bassel-Duby R, Olson EN. Prevention of muscular dystrophy in mice by CRISPR/Cas9-mediated editing of germline DNA. Science 2014;345:1184-1188.

87. Xu L, Park KH, Zhao L, et al. CRISPR-mediated genome editing restores dystrophin expression and function in mdx mice. Mol Ther 2016;24:564-569.

88. Ding Q, Strong A, Patel KM, et al. Permanent alteration of PCSK9 with in vivo CRISPR-Cas9 genome editing. Circ Res 2014;115:488-492.

89. Li HL, Fujimoto N, Sasakawa N, et al. Precise correction of the dystrophin gene in duchenne muscular dystrophy patient induced pluripotent stem cells by TALEN and CRISPR-Cas9. Stem Cell Reports 2015;4:143-154.
90. Park CY, Kim J, Kweon J, et al. Targeted inversion and reversion of the blood coagulation factor 8 gene in human iPS cells using TALENs. Proc Natl Acad Sci U S A 2014;111:9253-9258.

91. Park CY, Kim DH, Son JS, et al. Functional correction of large factor VIII gene chromosomal inversions in hemophilia A patient-derived iPSCs using CRISPR-Cas9. Cell Stem Cell 2015;17:213-220.

92. Hoban MD, Cost GJ, Mendel MC, et al. Correction of the sickle cell disease mutation in human hematopoietic stem/progenitor cells. Blood 2015;125:2597-2604.

93. Sebastiano V, Maeder ML, Angstman JF, et al. In situ genetic correction of the sickle cell anemia mutation in human induced pluripotent stem cells using engineered zinc finger nucleases. Stem Cells 2011;29:1717-1726.

94. Sun N, Zhao H. Seamless correction of the sickle cell disease mutation of the HBB gene in human induced pluripotent stem cells using TALENs. Biotechnol Bioeng 2014;111:1048-1053.

95. Huang X, Wang Y, Yan W, et al. Production of gene-corrected adult beta globin protein in human erythrocytes differentiated from patient iPSCs after genome editing of the sickle point mutation. Stem Cells 2015;33:1470-1479.

96. Xie F, Ye L, Chang JC, et al. Seamless gene correction of beta-thalassemia mutations in patient-specific iPSCs using CRISPR/Cas9 and piggyBac. Genome Res 2014;24:1526-1533.

97. Ma N, Shan Y, Liao B, et al. Factor-induced reprogramming and zinc finger nuclease-aided gene targeting cause different genome instability in beta-thalassemia induced pluripotent stem cells (iPSCs). J Biol Chem 2015;290:12079-12089.

98. Ye L, Wang J, Beyer AI, et al. Seamless modification of wild-type induced pluripotent stem cells to the natural CCR5Delta32 mutation confers resistance to HIV infection. Proc Natl Acad Sci U S A 2014;111:9591-9596.

99. Wilen CB, Wang J, Tilton JC, et al. Engineering HIV-resistant human $\mathrm{CD}_{4}+\mathrm{T}$ cells with $\mathrm{CXCR} 4$-specific zinc-finger nucleases. PLoS Pathog 2011;7:e1002020.

100. Sebastiano V, Zhen HH, Haddad B, et al. Human COL7A1-corrected induced pluripotent stem cells for the treatment of recessive dystrophic epidermolysis bullosa. Sci Transl Med 2014;6:264ra163.

101. Crane AM, Kramer P, Bui JH, et al. Targeted correction and restored function of the CFT'R gene in cystic fibrosis induced pluripotent stem cells. Stem Cell Reports 
2015;4:569-577.

102. Sargent RG, Suzuki S, Gruenert DC. Nuclease-mediated double-strand break (DSB) enhancement of small fragment homologous recombination (SFHR) gene modification in human-induced pluripotent stem cells (hiPSCs). Methods Mol Biol 2014;1114:279-290.

103. Firth AL, Menon T, Parker GS, et al. Functional gene correction for cystic fibrosis in lung epithelial cells generated from patient iPSCs. Cell Rep 2015;12:1385-1390.

104. Schwank G, Koo BK, Sasselli V, et al. Functional repair of CFTR by CRISPR/Cas9 in intestinal stem cell organoids of cystic fibrosis patients. Cell Stem Cell 2013;13:653-658.

105. Suzuki S, Sargent RG, Illek B, et al. TALENs facilitate single-step seamless SDF correction of F508del CFTR in airway epithelial submucosal gland cell-derived CF-iPSCs. Mol Ther Nucleic Acids 2016;5:e273.

106. Vierstra J, Reik A, Chang KH, et al. Functional footprinting of regulatory DNA. Nat Methods 2015;12:927-930.

107. Canver MC, Smith EC, Sher F, et al. BCLi1A enhancer dissection by Cas9-mediated in situ saturating mutagenesis. Nature 2015;527:192-197.

108. Rahman SH, Kuehle J, Reimann C, et al. Rescue of DNAPK signaling and T-cell differentiation by targeted genome editing in a prkdc deficient iPSC disease model. PLoS Genet 2015;11:e1005239.

109. Menon T, Firth AL, Scripture-Adams DD, et al. Lymphoid regeneration from gene-corrected SCID-X1 subject-derived iPSCs. Cell Stem Cell 2015;16:367-372.

110. Holt N, Wang J, Kim K, et al. Human hematopoietic stem/progenitor cells modified by zinc-finger nucleases targeted to CCR5 control HIV-1 in vivo. Nat Biotechnol 2010;28:839-847.

111. Li L, Krymskaya L, Wang J, et al. Genomic editing of the HIV-1 coreceptor CCR5 in adult hematopoietic stem and progenitor cells using zinc finger nucleases. Mol Ther 2013;21:1259-1269.

112. Nathwani AC, Tuddenham EG, Rangarajan S, et al. Adenovirus-associated virus vector-mediated gene transfer in hemophilia B. N Engl J Med 2011;365:2357-2365.

113. Nathwani AC, Reiss UM, Tuddenham EG, et al. Longterm safety and efficacy of factor IX gene therapy in hemophilia B. N Engl J Med 2014;371:1994-2004.

114. Hutter G, Nowak D, Mossner M, et al. Long-term control of HIV by CCR5 Delta32/Delta32 stem-cell transplantation. N Engl J Med 2009;360:692-698.

115. Tebas P, Stein D, Tang WW, et al. Gene editing of $\mathrm{CCR}_{5}$ in autologous $\mathrm{CD}_{4} \mathrm{~T}$ cells of persons infected with HIV. N Engl J Med 2014;370:901-910.

116. Badia R, Pauls E, Riveira-Munoz E, Clotet B, Este JA, Ballana E. Zinc finger endonuclease targeting PSIPı inhibits HIV-1 integration. Antimicrob Agents Chemother 2014;58:4318-4327.

117. Fadel HJ, Morrison JH, Saenz DT, et al. TALEN knockout of the PSIP1 gene in human cells: analyses of HIV-1 replication and allosteric integrase inhibitor mechanism. J Virol 2014;88:9704-9717.

118. White MK, Khalili K. CRISPR/Cas9 and cancer targets: future possibilities and present challenges. Oncotarget 2016;7:12305-12317.

119. Brown MT, Cooper JA. Regulation, substrates and functions of src. Biochim Biophys Acta 1996;1287:121-149.

120. Choi PS, Meyerson M. Targeted genomic rearrangements using CRISPR/Cas technology. Nat Commun 2014;5:3728.

121. Chen C, Liu Y, Rappaport AR, et al. MLL3 is a haploinsufficient 7q tumor suppressor in acute myeloid leukemia. Cancer Cell 2014;25:652-665.

122. Xue W, Chen S, Yin H, et al. CRISPR-mediated direct mutation of cancer genes in the mouse liver. Nature 2014;514:380-384.

123. Chiou SH, Winters IP, Wang J, et al. Pancreatic cancer modeling using retrograde viral vector delivery and in vivo CRISPR/Cas9-mediated somatic genome editing. Genes Dev 2015;29:1576-1585.

124. Tu Z, Yang W, Yan S, Guo X, Li XJ. CRISPR/Cas9: a powerful genetic engineering tool for establishing large animal models of neurodegenerative diseases. Mol Neurodegener 2015;10:35.

125. Hsu PD, Lander ES, Zhang F. Development and applications of CRISPR-Cas9 for genome engineering. Cell 2014;157:1262-1278.

126. Jusiak B, Cleto S, Perez-Pinera P, Lu TK. Engineering synthetic gene circuits in living cells with CRISPR technology. Trends Biotechnol 2016;34:535-547.

127. Wang Y, Cheng X, Shan Q, et al. Simultaneous editing of three homoeoalleles in hexaploid bread wheat confers heritable resistance to powdery mildew. Nat Biotechnol 2014;32:947-951.

128. Zhou Y, Zhu S, Cai C, et al. High-throughput screening of a CRISPR/Cas9 library for functional genomics in human cells. Nature 2014;509:487-491.

129. Diecke S, Jung SM, Lee J, Ju JH. Recent technological updates and clinical applications of induced pluripotent 
stem cells. Korean J Intern Med 2014;29:547-557.

130. Musunuru K. Genome editing of human pluripotent stem cells to generate human cellular disease models. Dis Model Mech 2013;6:896-904.

131. Grobarczyk B, Franco B, Hanon K, Malgrange B. Generation of isogenic human iPS cell line precisely corrected by genome editing using the CRISPR/Cas9 system. Stem Cell Rev 2015;11:774-787.

132. Orqueda AJ, Gimenez CA, Pereyra-Bonnet F. iPSCs: a minireview from bench to bed, including organoids and the CRISPR system. Stem Cells Int 2016;2016:5934782.

133. Maruyama T, Dougan SK, Truttmann MC, Bilate AM, Ingram JR, Ploegh HL. Increasing the efficiency of precise genome editing with CRISPR-Cas9 by inhibition of nonhomologous end joining. Nat Biotechnol 2015;33:538-542.

134. Chu VT, Weber T, Wefers B, et al. Increasing the efficiency of homology-directed repair for CRISPR-Cas9-induced precise gene editing in mammalian cells. Nat Biotechnol 2015;33:543-548.

135. Nakade S, Tsubota T, Sakane Y, et al. Microhomology-mediated end-joining-dependent integration of donor DNA in cells and animals using TALENs and CRISPR/Cas9. Nat Commun 2014;5:5560.

136. Sakuma T, Nakade S, Sakane Y, Suzuki KT, Yamamoto T. MMEJ-assisted gene knock-in using TALENs and CRISPR-Cas9 with the PITCh systems. Nat Protoc 2016;11:118133.

137. Ledford H. Bacteria yield new gene cutter. Nature 2015; 526:17.

138. Hsu PD, Scott DA, Weinstein JA, et al. DNA targeting specificity of RNA-guided Cas9 nucleases. Nat Biotechnol 2013;31:827-832.
139. Mali P, Aach J, Stranges PB, et al. CAS9 transcriptional activators for target specificity screening and paired nickases for cooperative genome engineering. Nat Biotechnol 2013;31:833-838.

140. Ran FA, Hsu PD, Lin CY, et al. Double nicking by RNA-guided CRISPR Cas9 for enhanced genome editing specificity. Cell 2013;154:1380-1389.

141. Fu Y, Sander JD, Reyon D, Cascio VM, Joung JK. Improving CRISPR-Cas nuclease specificity using truncated guide RNAs. Nat Biotechnol 2014;32:279-284.

142. Guilinger JP, Thompson DB, Liu DR. Fusion of catalytically inactive Cas9 to FokI nuclease improves the specificity of genome modification. Nat Biotechnol 2014;32:577582.

143. Tsai SQ, Wyvekens N, Khayter C, et al. Dimeric CRISPR RNA-guided FokI nucleases for highly specific genome editing. Nat Biotechnol 2014;32:569-576.

144. Hastie E, Samulski RJ. Adeno-associated virus at 50: a golden anniversary of discovery, research, and gene therapy success: a personal perspective. Hum Gene Ther 2015;26:257-265.

145. Moore R, Spinhirne A, Lai MJ, et al. CRISPR-based self-cleaving mechanism for controllable gene delivery in human cells. Nucleic Acids Res 2015;43:1297-1303.

146. Kormann MS, Hasenpusch G, Aneja MK, et al. Expression of therapeutic proteins after delivery of chemically modified mRNA in mice. Nat Biotechnol 2011;29:154-157.

147. Zuris JA, Thompson DB, Shu Y, et al. Cationic lipid-mediated delivery of proteins enables efficient protein-based genome editing in vitro and in vivo. Nat Biotechnol 2015;33:73-80. 